\title{
Association of HIV-infection, antiretroviral treatment and metabolic syndrome with large artery stiffness: a cross-sectional study
}

Titus F. Msoka ${ }^{1 *}$, Gary P. Van Guilder ${ }^{2}$, Yvo M. Smulders ${ }^{3}$, Marceline van Furth ${ }^{3}$, John A. Bartlett ${ }^{4}$ and Michiel A. van Agtmael ${ }^{3}$

\begin{abstract}
Background: Effective combined antiretroviral therapy (CART) has improved life expectancy among people living with HIV-1 infection. Treated HIV-1infection increases the prevalence of metabolic syndrome (MS). Despite sub-Saharan Africa having among the highest rates of HIV-1 infection, the effects of MS in HIV-1-infected individuals on cardiovascular risk is poorly explored. The aim of the study was to assess whether MS and/or HIV-1 treatment correlates with large elastic artery stiffness in HIV-1-infected patients treated with first-line CART.

Methods: The study sample comprised of 102 subjects free of cardiovascular disease and major risk factors divided into two groups based on HIV-1 infection, treatment, and MS status: $\mathrm{HIV}^{-} 1^{+} / \mathrm{CART}^{+} / \mathrm{MS}^{+}(n=12) ; \mathrm{HIV}^{-} 1^{+} / \mathrm{CART}^{-} / \mathrm{MS}^{+}(n=16)$; $\mathrm{HIV}-1^{-} / \mathrm{MS}^{+}(n=10) ; \mathrm{HIV}^{-1}{ }^{+} / \mathrm{CART}^{+} / \mathrm{MS}^{-}(n=42) ; \mathrm{HIV}^{-1}{ }^{+} / \mathrm{CART} / \mathrm{MS}^{-}(n=32) ; \mathrm{HIV}^{-}{ }^{-} / \mathrm{MS}^{-}(n=39)$. MS was established according the International Diabetes Federation definition. Large artery stiffness was measured using applanation tonometry to assess aortic pulse wave velocity (aPM) and aortic augmentation index at heart rate of $75 \mathrm{bpm}$ (Alx@HR75). cART included lamivudine/zidovudine and nevirapine or efavirenz.
\end{abstract}

Results: The prevalence of MS in the HIV-1-infected patients was 28\%. There were no significant differences in aPWV in the non-MS groups. However, in subjects with MS, aPWW was significantly higher in the HIV-1 CART patients $(9.0 \pm 1.9$ $\mathrm{m} / \mathrm{s})$ compared with both controls $(7.5 \pm 1.8 \mathrm{~m} / \mathrm{s} ; P=0.018)$ and untreated HIV-1 patients $(7.7 \pm 1.3 \mathrm{~m} / \mathrm{s} ; P=0.023)$, and these differences remained after adjustment for blood pressure and sex. Aortic PWW was significantly elevated $(P=0$. 009) in HIV-1 CART patients with MS compared to their counterparts without MS. Untreated HIV-1 patients with MS also demonstrated increased aPW compared to their counterparts without MS $(P=0.05)$. Aortic Alx@HR75 was, on average, $\sim 5 \%$ higher in HIV-1 cART patients with MS $(28.3 \pm 62 \%$ compared with untreated HIV-1 patients with MS $(23.5 \pm 9 \% ; P=$ 0.075). Sub-group multivariate analysis identified MS as an independent predictor of increased aPWV in HIV-1 CART patients.

Conclusions: Our study established that presence of MS in HIV-1 patients on treatment was associated with increased aPWV and hence increased arterial stiffness in sub-Saharan African HIV-1 patients on first-line cART.

Keywords: Metabolic syndrome, Pulse wave velocity, Augmentation index, Cardiovascular risk, First-line combined antiretroviral therapy

\footnotetext{
* Correspondence: ftitus2001@yahoo.co.uk

'Department of Internal Medicine, Kilimanjaro Christian Medical Centre,

Moshi, Tanzania

Full list of author information is available at the end of the article
}

(c) The Author(s). 2019, corrected publication January 2019. Open Access This article is distributed under the terms of the Creative Commons Attribution 4.0 International License (http://creativecommons.org/licenses/by/4.0/), which permits

unrestricted use, distribution, and reproduction in any medium, provided you give appropriate credit to the original author(s) and the source, provide a link to the Creative Commons license, and indicate if changes were made. The Creative Commons Public Domain Dedication waiver (http://creativecommons.org/publicdomain/zero/1.0/) applies to the data made available in this article, unless otherwise stated. 


\section{Background}

Effective use of combined antiretroviral therapy (cART) has improved life expectancy among people living with HIV-1infection [1]. Despite immunological modulation, aging with HIV-1 infection is linked with an increased prevalence of metabolic syndrome (MS), both in the absence and presence of cART, which can accelerate the development of vascular abnormalities, particularly endothelial dysfunction [2] and increased carotid-artery media thickness [3]. In fact, large elastic artery stiffness, a marker of heightened cardiovascular risk and an independent predictor of adverse vascular events [4], is elevated in HIV-1-infected patients in North America and Europe [5] and appears to be further increased the presence of cART $[6,7]$. We have previously shown that first-line cART with non-nucleoside and nucleoside reverse transcriptase inhibitors and time since HIV-1 diagnosis were independent predictors of increased large elastic artery stiffness in sub-Saharan African HIV-1-infected patients [8], largely free of clustered cardiometabolic risk factors that comprise MS. Data are limited and findings have been inconsistent in sub-Saharan African HIV-1-infected patients [9, 10], even though antiretroviral treatment and arterial stiffening could contribute to accelerated atherosclerotic disease. It is possible that the inconsistencies arise in part because HIV-1 infection and cART are both associated with a spectrum of metabolic complications such as dyslipidemia, insulin resistance, changes in body fat distribution, and increased blood pressure [9], which can impact arterial stiffening [11]. Despite sub-Saharan Africa having the highest rates of HIV-1 infection [10], MS in relation to arterial stiffness in HIV-1-infected patients is poorly explored.

The present study aimed to determine: 1) if MS is associated with increased large elastic artery stiffness in HIV-1-infected patients; and 2) if HIV-1 treatment with combination non-nucleoside and nucleoside reverse transcriptase inhibitors is associated with increased arterial stiffness compared to untreated patients.

\section{Methods}

\section{Study participants}

One-hundred twenty-seven HIV-1-infected adult patients (52 treatment-naive and 75on cART) were recruited from the Infectious Disease Clinic (IDC) of the Kilimanjaro Christian Medical Center (KCMC) in northern Tanzania to participate in this cross-sectional comparative hospital-based study. $\mathrm{KCMC}$ is a referral hospital in the northern zone in Tanzania serving $\sim 13$ million patients. The IDC provides care to approximately $2000 \mathrm{HIV}$-1-infected patients free of charge with services including, but not limited to, counseling, testing and treatment. The process for recruitment and screening of the participants and the inclusion/exclusion criteria have been described elsewhere [8].
The final study sample included 102 HIV-1 patients: 48 untreated HIV-1-infected (32 without MS; 16 with MS) and 54 HIV-1-infected patients on cART (42 without MS; 12 with MS). MS was established according the International Diabetes Federation (IDF) ethnic-specific definition [11]. Antiretroviral regimens used by HIV-1 patients on cART have been described elsewhere [8]. Forty-nine HIV-1 uninfected adults (39 with MS, 10 without MS) served as controls. KCMC hospital staff and surrounding community were recruited to serve as uninfected controls and were well matched to the HIV-1 patients in terms of age and BMI. The absence of plasma HIV-1 RNA was confirmed in control subjects via real time PCR. Control subjects were screened via medical history and physical examination by medical staff affiliated with KCMC; those that presented with hepatic, renal, haematological, or cardiovascular disease, stroke, or diabetes were excluded. None of the study participants smoked. Informed consent was requested and given by all study participants. Study approval was provided by the Institutional Ethics Committee at KCMC via ethical clearance number 382. Study experiments conformed to the Helsinki Declaration.

\section{Body composition, metabolic and large artery stiffness measurements}

The methods to measure body mass, height, abdominal obesity, percent body fat, fasting plasma lipid, lipoprotein, glucose concentrations, $\mathrm{CD} 4^{+} \mathrm{T}$ cell count at the time of cART initiation, estimation of percent fat, blood pressure and large artery measurements have been described previously [8].

\section{Statistical analysis}

Between-groups ANOVA method was used to determine any differences between subject characteristics. Group differences in aPWV andAIx@HR75 were determined by General Linear Model univariate ANOVA. When indicated by a significant $\mathrm{F}$ value, a post-hoc test using the Tukey HSD method was performed to identify specific group differences. Velocity values were adjusted for mean arterial pressure since it is well established that arterial pressure may be a confounder of increased arterial stiffness [12] and should be taken into account when interpreting aPWV [13]. Details of statistical analyses performed have been described elsewhere [8]. MS, age, sex, and presence of cART were included as dummy (dichotomy) explanatory variable in the multiple regression model. IBM SPSS Statistics for Windows software (version 24; IBM Corp., Armonk, N.Y., USA) was utilized for statistical analyses.

\section{Results}

Participant characteristics according to sub-groups are shown in Table 1. The point prevalence of MS in the HIV-1 patients was $28 \%$. Subjects without MS were 
Table 1 Patient characteristics with and without metabolic syndrome

\begin{tabular}{|c|c|c|c|c|c|c|}
\hline \multirow[b]{3}{*}{ Variable } & \multicolumn{3}{|c|}{ No Metabolic Syndrome } & \multicolumn{3}{|c|}{ Metabolic Syndrome } \\
\hline & \multicolumn{3}{|l|}{$(N=113)$} & \multicolumn{3}{|l|}{$(N=38)$} \\
\hline & $\begin{array}{l}\text { Controls } \\
(n=39)\end{array}$ & $\begin{array}{l}\text { HIV-1 untreated } \\
(n=32)\end{array}$ & $\begin{array}{l}\text { HIV-1 cART } \\
(n=42)\end{array}$ & $\begin{array}{l}\text { Controls } \\
(n=10)\end{array}$ & $\begin{array}{l}\text { HIV-1 untreated } \\
(n=16)\end{array}$ & $\begin{array}{l}\text { HIV-1 CART } \\
(n=12)\end{array}$ \\
\hline Age, year & $45 \pm 3$ & $44 \pm 6$ & $46 \pm 5$ & $45 \pm 4$ & $47 \pm 5$ & $47 \pm 4$ \\
\hline Men, \% & 69 & 28 & 29 & 50 & 13 & 25 \\
\hline Body mass, kg & $67.8 \pm 11.8$ & $64.7 \pm 9.7$ & $58.5 \pm 11.5^{a}$ & $81.1 \pm 10.6^{c}$ & $71.2 \pm 12.7^{c}$ & $75.0 \pm 15.6^{c}$ \\
\hline $\mathrm{BMl}, \mathrm{kg} / \mathrm{m}^{2}$ & $24.8 \pm 4.2$ & $24.3 \pm 3.9$ & $22.5 \pm 4.1^{a}$ & $30.4 \pm 4.6^{c}$ & $26.7 \pm 3.2^{c}$ & $28.9 \pm 4.1^{c}$ \\
\hline Body fat, $\%$ & $32 \pm 9$ & $35 \pm 7$ & $33 \pm 8$ & $38 \pm 5^{c}$ & $40 \pm 4^{c}$ & $40 \pm 4^{c}$ \\
\hline Waist circumference, cm & $85 \pm 10$ & $81 \pm 7$ & $81 \pm 11$ & $95 \pm 8^{c}$ & $92 \pm 9^{c}$ & $98 \pm 6^{c}$ \\
\hline Systolic BP, mmHg & $124 \pm 12$ & $126 \pm 9$ & $120 \pm 11$ & $135 \pm 7^{c}$ & $135 \pm 13^{c}$ & $131 \pm 18^{c}$ \\
\hline Diastolic BP, mmHg & $74 \pm 7$ & $76 \pm 5$ & $74 \pm 8$ & $79 \pm 3^{c}$ & $79 \pm 6$ & $79 \pm 6^{c}$ \\
\hline LDL-cholesterol, mmol/l & $2.9 \pm 0.9$ & $2.5 \pm 0.8$ & $2.7 \pm 1.0$ & $3.1 \pm 0.7$ & $2.8 \pm 1.1$ & $3.2 \pm 0.9$ \\
\hline HDL-cholesterol, mmol// & $1.2 \pm 0.4$ & $1.1 \pm 0.5$ & $1.4 \pm 0.6^{b}$ & $1.0 \pm 0.6$ & $0.8 \pm 0.3$ & $1.1 \pm 0.3$ \\
\hline Triglycerides, mmol/l & $1.1 \pm 0.7$ & $1.0 \pm 0.4$ & $1.4 \pm 1.1$ & $2.3 \pm 1.5^{c}$ & $1.3 \pm 0.6$ & $2.0 \pm 1.2$ \\
\hline Glucose, mmol/l & $4.7 \pm 0.6$ & $4.5 \pm 0.7$ & $4.8 \pm 0.6$ & $5.0 \pm 0.7$ & $4.8 \pm 0.9$ & $4.7 \pm 0.7$ \\
\hline 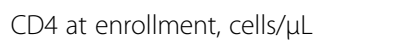 & - & $665 \pm 142$ & $289 \pm 46^{b}$ & - & $666 \pm 120$ & $302 \pm 41^{b}$ \\
\hline CD4 (most recent), cells/uL & - & $493 \pm 250^{d}$ & $494 \pm 229^{d}$ & - & $430 \pm 255^{d}$ & $480 \pm 189^{d}$ \\
\hline Months of HIV-1 infection, median & - & 21.5 & $29.3^{b}$ & - & 20.6 & $39.8^{b}$ \\
\hline Months cART, median & - & - & 24.0 & - & - & 30.9 \\
\hline
\end{tabular}

Values are means $\pm S D$ unless otherwise noted. $B M I$ body mass index, $B P$ blood pressure, $L D L$ low-density lipoprotein, $H D L$ high-density lipoprotein, $C A R T$ combined antiretroviral therapy, ${ }^{a} P<0.05$ vs. within-group controls, ${ }^{b} P<0.05$ vs. within-group HIV-1 untreated patients, ${ }^{c} P<0.05$ vs. corresponding group without metabolic syndrome, ${ }^{d} P<0.01$ vs. within-group CD4 at enrollment

generally well matched, however, HIV-1-cART patients had lower body mass and BMI compared with corresponding group controls. As expected, body mass, BMI, percent body fat, and waist circumference were higher (all $P<0.05$ ) in subjects with MS compared to corresponding between-group subjects without MS. There were no significant differences in indices of adiposity, blood pressure, or plasma lipids, lipoproteins, and glucose among the controls, HIV-1 untreated patients, and HIV-1-cART patients with MS.

No differences were seen in the most recent CD4+ T cell counts between untreated and cART HIV-1 patients regardless of MS. There were no significant differences in the duration of HIV-1 infection between untreated and cART HIV-1 patients with MS compared to those without. There were no differences in the median duration of cART between the HIV-1 patients with MS (24 months; IQR: 15.9 to 42.3 months, $P=0.07$ ) compared with HIV-1 patients without MS (30.9 months; IQR: 23.2 to 66.4 months, Table 1 ).

\section{Hemodynamics}

Hemodynamic results from the time of pulse wave analysis are displayed in Table 2. Peripheral systolic and mean arterial pressures and pulse rates were higher, and peripheral diastolic pressure lower in comparison to central values in both the MS group and in patients without MS $(P<0.001$ for all $)$. No differences were seen among the groups in central systolic, diastolic, mean arterial, or pulse pressures. Similarly, corresponding peripheral blood pressures were not different among the groups.

Aortic pulse wave velocity in the cohort of HIV-1 patients There were no differences in aPWV between all HIV-1 seropositive patients (untreated grouped with cART patients) compared with seronegative control patients (data not shown). Similar to our earlier publication [8], HIV-1 cART patients $(7.9 \pm 1.9 \mathrm{~m} / \mathrm{s} ; \quad P=0.008)$ demonstrated elevated aPWV compared with untreated HIV-1 patients $(7.1 \pm 1.2 \mathrm{~m} / \mathrm{s})$.

\section{Aortic pulse wave velocity in patients with metabolic syndrome}

In the entire study cohort combined by MS status, subjects with MS had significantly elevated aPWV $(8.3 \pm 1.6$ $\mathrm{m} / \mathrm{s} ; P<0.001)$ compared with subjects without MS (7.1 $\pm 1.3 \mathrm{~m} / \mathrm{s}$ ). Subgroup analysis in subjects without MS showed that there were no significant differences in aPWV between controls, HIV-1 untreated patients, and HIV-1 cART patients $(P=0.464$; Fig. $1 \mathrm{~A})$. However, there was a significant main effect of MS among the three groups $(P=0.008)$, such that in the HIV-1 cART patients with MS, aPWV was $25 \%(P=0.018)$ and $21 \%$ $(P=0.023)$ higher compared with both controls and untreated HIV-1 patients, respectively. In addition, aPWV 
Table 2 Central and peripheral hemodynamic data during pulse wave analysis in patients with and without metabolic syndrome

\begin{tabular}{|c|c|c|c|c|c|c|}
\hline \multirow{3}{*}{ Variable } & \multicolumn{3}{|c|}{ No Metabolic Syndrome } & \multicolumn{3}{|c|}{ Metabolic Syndrome } \\
\hline & Controls & HIV-1 untreated & HIV-1 CART & Controls & HIV-1 untreated & HIV-1 CART \\
\hline & $(n=39)$ & $(n=32)$ & $(n=42)$ & $(n=10)$ & $(n=16)$ & $(n=12)$ \\
\hline Central systolic BP & $113 \pm 12$ & $116 \pm 10$ & $114 \pm 10$ & $126 \pm 7^{c}$ & $120 \pm 13$ & $110 \pm 11^{b}$ \\
\hline Peripheral systolic BP & $123 \pm 13^{a}$ & $127 \pm 11^{a}$ & $124 \pm 11^{a}$ & $135 \pm 7^{a c}$ & $129 \pm 11^{a}$ & $120 \pm 13^{a}$ \\
\hline Central diastolic BP & $75 \pm 7$ & $78 \pm 6$ & $78 \pm 8$ & $81 \pm 3^{c}$ & $78 \pm 6$ & $74 \pm 7^{b}$ \\
\hline Peripheral diastolic BP & $74 \pm 7^{a}$ & $77 \pm 6^{a}$ & $76 \pm 8^{a}$ & $79 \pm 3^{a c}$ & $72 \pm 7^{a}$ & $72 \pm 7^{a b}$ \\
\hline Central MAP & $87 \pm 8$ & $91 \pm 7$ & $90 \pm 9$ & $96 \pm 3^{c}$ & $92 \pm 7$ & $86 \pm 8^{b}$ \\
\hline Peripheral MAP & $90 \pm 8^{a}$ & $93 \pm 7^{a}$ & $92 \pm 8^{a}$ & $98 \pm 2^{a c}$ & $94 \pm 7^{a}$ & $87 \pm 8^{b c}$ \\
\hline Central PP & $38 \pm 9$ & $38 \pm 8$ & $36 \pm 7$ & $45 \pm 8^{c}$ & $41 \pm 9$ & $36 \pm 8$ \\
\hline Peripheral PP & $49 \pm 10^{a}$ & $50 \pm 10^{a}$ & $47 \pm 7^{a}$ & $56 \pm 9^{a}$ & $52 \pm 9^{a}$ & $45 \pm 8^{a b}$ \\
\hline PP amplification (ratio) & $1.33 \pm 0.17$ & $1.33 \pm 0.14$ & $1.32 \pm 0.13$ & $1.24 \pm 0.12$ & $1.29 \pm 0.12$ & $1.25 \pm 0.19$ \\
\hline Heart rate (beats/min) & $67 \pm 11$ & $76 \pm 10^{b}$ & $74 \pm 11^{b}$ & $66 \pm 7$ & $74 \pm 6$ & $78 \pm 13^{b}$ \\
\hline
\end{tabular}

Values $(\mathrm{mmHg})$ are means \pm SD. CART combined antiretroviral therapy, $B P$ blood pressure, MAP mean arterial pressure, $P P$ pulse pressure, ${ }^{a} P<0.001$ for withingroup central variable, ${ }^{b} P<0.01$ versus within-group controls, ${ }^{c} P<0.001$ vs. no metabolic syndrome controls

was significantly elevated $(P=0.009)$ in HIV-1 cART patients with MS compared to their cART counterparts without MS (Figure1A). The markedly higher aPWV in the HIV-1 cART patients with MS compared with the other MS groups remained after inclusion of mean arterial pressure as a covariate $(\mathrm{P}=0.009)$. These differences also remained after adjustment for sex $(P=0.011)$. There was no difference in aPWV in untreated HIV-1 patients with MS $(7.7 \pm 1.3 \mathrm{~m} / \mathrm{s}) \quad$ compared to their untreated counterparts without MS $(7.1 \pm 1.6 \mathrm{~m} / \mathrm{s} ; P=0.139)$. Similarly, aPWV was similar in controls with and without MS $(P=0.590)$.

\section{Aortic augmentation in the cohort of HIV-1 patients}

There were no differences in AIx@HR75 between all HIV-1 seropositive patients (untreated grouped with cART patients) compared with seronegative control patients (data not shown). Similar to our earlier publication
[8], HIV-1 cART patients $(27.8 \pm 9 \% ; P=0.005)$ demonstrated elevated AIx@HR75 compared with untreated HIV-1 patients (22.7 $\pm 10 \%)$.

\section{Aortic augmentation in the patients with metabolic syndrome}

There was no main effect $(P=0.338)$ of MS with respect to aortic AIx@HR75 when the study cohort was combined by MS status. Likewise, subgroup analysis in subjects without MS showed no differences in aortic AIx@HR75 between controls, HIV-1 untreated patients, and HIV-1 cART patients $(P=0.076$; Fig. $1 \mathrm{~B})$ after sex adjustment. In addition, there were no differences in AIx@HR75 $(P=0.092)$ among the groups with MS. In contrast to the aPWV data, aortic AIx@HR75 was not different $(P=0.892)$ in HIV-1 cART patients with MS $(28.3 \pm 6.2 \%$ compared to their cART counterparts without MS (27.7 $\pm 9.7 \%$; Fig. 1B).
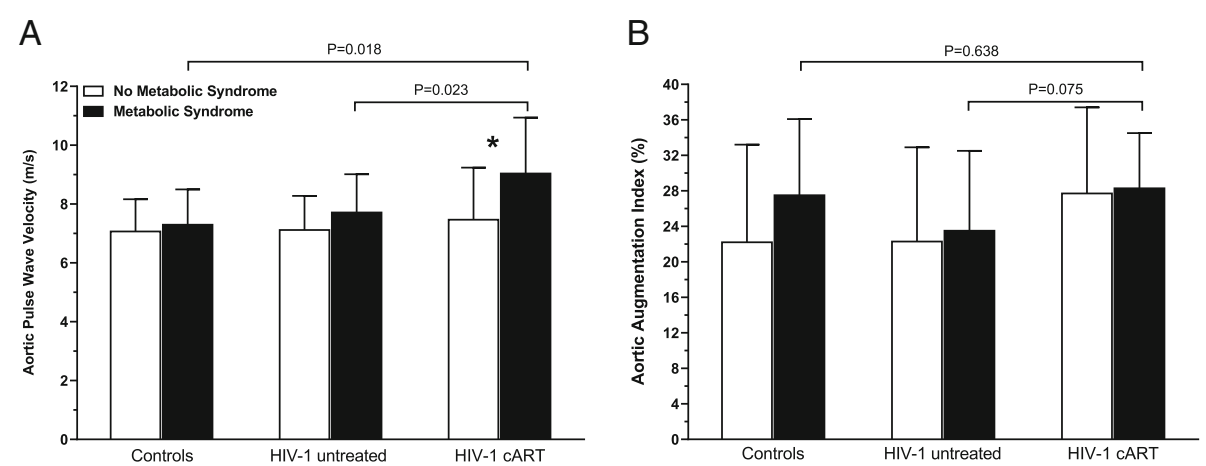

Fig. 1. Blood pressure- and sex-adjusted aortic pulse wave velocity (a) and aortic augmentation index (b) in the controls, HIV-1-naive and HIV-1CART patients with and without metabolic syndrome. Aortic pulse wave velocity was $25 \%(P=0.018)$ and $21 \%(P=0.023)$ higher in the HIV- 1 cART patients compared with both controls and untreated HIV-1 patients, respectively. There was no significant main effect of metabolic syndrome on augmentation index between the three groups. Values are mean \pm SD.* $P=0.009$ versus HIV- 1 CART patients without metabolic syndrome 
Independent predictors of large elastic artery stiffness

To identify variables that were independent predictors of aPWV in the combined sample of HIV-1 patients, we performed stepwise multiple linear regression analyses. MS, age, sex, presence of cART, included as a dummy explanatory variable (yes or no), duration of cART, body mass, LDL-cholesterol, duration of HIV-1 infection, $\mathrm{CD}^{+} \mathrm{T}$ cells at enrolment and most recent, viral load, and mean arterial pressure were included in the stepwise regression. In Table 3 a prediction model is displayed, with statistical significance $(F=9.901, p<0.0001)$ and it accounted for $29 \%$ of the variance of aPWV $\left(R^{2}=0.290\right.$, Adjusted $\left.R^{2}=0.261\right)$. MS $(\beta=0.220)$, age $(\beta=0.235)$, duration of cART $(\beta=0.275)$, and mean arterial pressure $(\beta=0.222) \quad$ independently predicted aPWV, with presence of MS a stronger predictor. After including additional covariates (sex, LDL and HDL-cholesterol, triglycerides, and anthropometrics), the independent contributions of the predictors remained significant in the regression model. Examination of the structure coefficients further supports that MS was a strong determinant of aPWV among the HIV-1-infected patients. The squared structure coefficient for $M S$ was 0.40 , indicating that of the $29 \%\left(R^{2}\right)$ effect, $M S$ independently accounts for $40 \%$ of the explained variance in aPWV when all other predictors are held constant. Moreover, the presence of MS was independently related to a $0.8 \mathrm{~m} / \mathrm{s}$ increase in aPWV after controlling for the effects of age, duration of CART, and blood pressure.

To corroborate the independent effects of MS to predict changes in aPWV in the HIV-1 cART patients, we performed a separate stepwise multivariate regression analysis in this group after omitting untreated HIV-1 patients. After controlling for all potential covariates in the model, MS remained the independent predictor of aPWV $(\beta=0.448, P=0.001)$ in the HIV-1 cART patients. In the HIV-1 untreated patients alone, age $(\beta=0.468, \mathrm{P}$ $=0.001$ ) was the only independent predictor of aPWV.

Examining AIx@HR75, MS was not a significant predictor in the combined HIV-1 group (HIV-1 untreated and HIV-1 cART). Rather, duration of cART $(\beta=0.288)$, diastolic pressure $(\beta=0.301)$, and sex $(\beta=0.192)$ independently predicted aortic AIx. The model was statistically significant $(F=8.041, P<0.0001)$ and accounted for $\sim 17 \%$ of the variance of aortic AIx@HR75 $\left(R^{2}=0.198\right.$, Adjusted $\mathrm{R}^{2}=0.173$ ).

In the uninfected control group, a stepwise multivariate regression was also performed to identify independent predictors of aPWV. After controlling for all potential covariates in the model, the only significant predictor of aPWV in the control group was diastolic pressure $(\beta=0.405, P=0.004)$.

\section{Discussion}

The main findings of the present study were that MS and other risk variables (i.e., blood pressure, duration of cART, and age) are associated with increased large elastic artery stiffness in in sub-Saharan African HIV-1-infected patients. Importantly, the degree of arterial stiffness in HIV-1 patients with MS is worse in the presence of combination non-nucleoside and nucleoside reverse transcriptase inhibitors. This suggests that perhaps treated HIV-1 infection coupled with clustering of risk factors of MS may increase aPWV and hence arterial stiffness. Increased arterial stiffness may represent an important link contributing to atherosclerotic vascular disease associated with HIV-1 infection and cART. It would benefit practitioners, and be clinically advantageous to treated HIV-1 infected individuals with MS to discriminate between those with and without increased arterial stiffness, in sub-Saharan Africa HIV-1 patients.

Our findings showed that aPWV was significantly elevated in individuals with MS compared to their counterparts without MS. Other studies also reported elevated aPWV in individuals with MS compared to those without $[14,15]$. Further analysis demonstrated that HIV-1 cART patients compared to their cART-naive counterparts had significantly higher aPWV. These findings corroborate similar studies [7, 8, 16]. HIV-1 cART with MS compared to HIV-1 cART-naive and controls with MS had a significant elevated aPWV even after inclusion of mean arterial pressure as a covariate and after adjustment for sex. Furthermore, a significant difference was observed in arterial stiffness when HIV-1 cART patients with MS were compared to HIV-1 cART patients without MS. However, no significant elevation in aPWV was noted between untreated HIV-1 patients with MS and their counterparts without MS. Similar findings have been reported in a study

Table 3 Independent predictors of aortic PWV in the combined HIV-1 untreated and HIV-1 cART patients

\begin{tabular}{lllllll}
\hline & Predictor Variables & Multiple $R$ & $R$ square & Unstandardized regression coefficient (B) & $95 \%$ Confidence Interval & $P$ \\
\hline Aortic PWV (m/s) & metabolic syndrome & 0.341 & 0.116 & 0.816 & $0.135,1.497$ & 0.019 \\
& Age & 0.447 & $0.200^{*}$ & 0.072 & $0.018,0.126$ & 0.009 \\
& duration of CART & 0.503 & $0.253^{*}$ & 0.022 & $0.008,0.036$ & 0.002 \\
& MAP & 0.541 & $0.293^{*}$ & 0.051 & $0.007,0.094$ & 0.023 \\
\hline
\end{tabular}

The independent predictor variables entering the final model are reported. PWV pulse wave velocity, $C A R T$ combined antiretroviral therapy *Significant $\mathrm{F}$ change in the $\mathrm{R}$ square $(P<0.001)$ 
done in Italy [17], though they did not find significant differences between HIV-1 cART and HIV-1 cART-naive patients with MS. The fact that there was no difference in aPWV in untreated HIV-1 patients with MS compared to their untreated counterparts without MS would imply that cART together with MS impacts aPWV. It is argued that systemic inflammation of any cause could initiate the process of endothelial damage which is characterized by abnormal orientation of endothelial cells in the direction of blood flow in contact with the vessel wall [18]. According to Monsuez et al. [19] the molecular mechanisms by which HIV-1 induces endothelial dysfunction are multifactorial with several theories linking them with combinations of high viral load, elevated inflammatory markers and adhesion molecules, pro-atherogenic lipid profile and the effects of cART. Contrary to our findings, a study in sub-Saharan Africa found higher prevalence of MS and increased arterial stiffness in cART-naive HIV-infected individuals compared to healthy individuals in Cameroon [20]. However, the study did not involve either HIV-infected individual on cART or stratify the groups according to MS status. Also, a review of arterial stiffness and HIV infection in adult Africans concluded that arterial stiffness is elevated in HIV-infected individuals regardless of antiretroviral treatment status [21].

Upon stepwise multivariate analysis, independent predictors of aPWV were found to be presence of MS, age, duration of CART and mean arterial pressure. Further subgroup analysis revealed that in the HIV-1 cART group, MS remained the only predictor of aPWV while in the HIV-1 cART-naive group only age predicted aPWV. This could imply that treated HIV-1 infection coupled with the presence of MS is associated with increased aPWV and hence arterial stiffness. Similar to our study findings, the study by Maloberti et al. [17] demonstrated that pulse wave velocity was elevated in HIV patients on treatment with MS than in their counterparts without MS indicative of independent effect of MS on pulse wave velocity. Also, consistent to our study findings, Rider et al. [16] found that MS had an additive effect to HIV-1 on elevated aPWV. However, they concluded that, independent of MS, patients with treated HIV-1 have reduced vascular function and that the magnitude of the effect of treated HIV infection is the same as that of the MS. One possible explanation of the effect of cART is on lipid metabolism, endothelial and adipocyte cell function and mitochondrial dysfunction [22]. Also, cART may activate pro-inflammatory cytokines which are a result of infection and inflammation. These abnormalities are believed to lead to antiretroviral-associated metabolic syndrome [23]. Different organs and organ systems are affected by systemic complications as a result of MS. One characteristic of MS is that it is associated with alterations of the arterial vasculature, especially of the endothelium, and basal membrane and also polymorphonuclear activation, increased oxidative stress, and changes in the expression of matrixmetalloproteinases (MMPs) - family of enzymes essential for degradation of extracellular matrix during the embryonic development, morphogenesis and tissue remodeling [24, 25]. Medley et al. [26] point out that, MMP-9 in particular, could be associated with large artery stiffening and hence vascular disease. It is suggested that, the extracellular matrix of the vessel walls that are made up of collagen and elastin [27] are closely related to structural strength and elasticity of the blood vessels and are regulated by catabolic MMPs. MMPs degrade the extracellular matrix by affecting the production of weaker collagen and worn elastin fibers leading to arterial stiffening [28]. On the other hand, vascular stiffening may be a result of a complex interplay between various independent and inter-dependent factors which include age, the hormonal situation, the individual's glycemic state and salt intake, as well as the global decline in cellular systems and function [27].

Contrary to aPWV, we did not observe differences in AIx@HR75 between HIV-1 cART patients with MS compared to their cART counterparts without MS. Several studies have shown a dissociation of aortic pulse wave velocity and augmentation index in patients with MS and healthy individuals. For example, Vlachopoulos et al. [29] found that circulating MMPs in healthy persons were inversely associated with large artery stiffness determined by aPWV, but not with wave reflections, which are measured by AIx. In their earlier randomized, double blind, sham procedure-controlled study in healthy subjects, Vlachopoulos et al. [30] found that acute systemic inflammation leads to increases large artery stiffness and a decrease in aortic AIx. Similar findings on the dissociation between aPWV and AIx were revealed in a study done by Vágovicová et al. [31] regarding the association of MS with arterial properties. They reported that aPWV was higher in subjects with MS compared with those without. In addition, aPWV was elevated in subjects with a greater number of MS risk factors. In contrast, AIx was lower in subjects with a higher number of MS risk factors, even after adjustment for age gender heart rate and mean arterial pressure. The possible explanation for the dissociation between aPWV and AIx as indicators of arterial stiffness could be that inflammation increases PWV resulting in an early return of wave reflections to central arteries. At the same time, it induces vasodilation and thus decreases the magnitude of reflected waves culminating in a neutral or decreased net result of wave reflection indices. On the other hand, Cheng and Holewijn et al. $[32,33]$ pointed out the dissociation could be due to the discrepancy in the AIx formula; arguing that, the AIx formula has other factors apart from central second peak and augmentation pressure and hence cannot be solely attributed to changes in central second peak and augmentation pressure. However, this needs further validation. 
In this study we found the point prevalence of MS among HIV-1-infected patients was $28 \%$. This is consistent with prevalence data reported in other studies in Tanzania [34, 35] and similar to studies in the developed world [36-38]. However, great variations in prevalence of MS have been reported in other sub-Sahara African countries ranging from 11\% in Botswana [39] to 58\% in Uganda [40] among self-reported adherent HIV-infected patients using at least two MS components. The differences could be attributed by the sample size and/or difference in MS criteria used. The reported high prevalence of MS in HIV-1 infected in the Ugandan study could be due to involvement of only cART-adherent study population with no substitutions which other studies do not specify.

\section{Clinical perspective}

This study shows that metabolic syndrome (MS) in treated HIV patients further contributes to CVD risk as measured by arterial stiffness. It should make the clinician extra aware of the importance of CVRM (smoking, blood pressure, lipids, and lifestyle) in HIV patients with MS.

During screening our study excluded patients with clinical evidence of cardiometabolic disease, known to stiffen arteries. By excluding these patients we aimed at removing variables that could have directly influenced the outcome variable. The observational nature of the study limits the establishment of the direct causative effect MS on arterial stiffness. Moreover, the small sample size and even smaller sub-groups with/without MS limits the power to detect important associations as well.

\section{Conclusion}

In conclusion, in stark contrast to HIV-1 treatment-naive patients with MS, the presence of MS was associated with more severe large elastic arterial stiffening in HIV-1 patients treated with combination non-nucleoside and nucleoside reverse transcriptase inhibitors. In addition, the large artery stiffness was greater in HIV-1 cART patients with MS compared to treated patients free of MS. These findings suggest that while cART may contribute to the development of MS, it may also exaggerate the development of arterial remodeling.

\footnotetext{
Abbreviations

${ }^{\circ} \mathrm{C}$ : degrees Celsius; Aix: Augmentation index; Alx@HR75: Aortic augmentation index at heart rate of 75 beats per minute; ANOVA: Analysis of variance; aPWV: Aortic pulse wave velocity; BMl: Body mass index; CART: Combination antiretroviral therapy; $\mathrm{CD}^{+} \mathrm{T}$ : Cluster of differentiation 4 of T cells; CVRM: Cardiovascular Risicomanagement; ECG: Electrocardiogram; HDL: High density lipoprotein; HIV-1: Human Immuno-deficiency virus type 1; HIV-1: RNA human Immuno-deficiency virus type 1Ribo-nucleic acid; $\mathrm{HIV}^{-1}{ }^{-}$/ $\mathrm{MS}^{-}$: HIV-1-uninfected without metabolic syndrome; HIV-1-/ $\mathrm{MS}^{+}$: HIV-1uninfected with metabolic syndrome; HIV-1 ${ }^{+} / \mathrm{CART}^{-} / \mathrm{MS}^{-}$: HIV-1-infected without metabolic syndrome and not on antiretroviral therapy; $\mathrm{HIV}-1^{+}$/ $\mathrm{CART}^{-} / \mathrm{MS}^{+}$: HIV-1-infected with metabolic syndrome and not on antiretroviral therapy; $\mathrm{HIV}-1^{+} / \mathrm{CART}^{+} / \mathrm{MS}^{-}$: HIV-1-infected without metabolic syndrome and on antiretroviral therapy; $\mathrm{HIV}_{-} 1^{+} / \mathrm{CART}^{+} / \mathrm{MS}^{+}$: HIV-1-infected with metabolic syndrome and on antiretroviral therapy; HSD: Honest
}

significance of differentiation; IDC: Infectious diseases clinic; IDF: International diabetes federation; IQR: Inter-quartile range; KCMC: Kilimanjaro Christian medical center; KCMC-IDC: Kilimanjaro Christian medical center- infectious diseases clinic; KCMUCo: Kilimanjaro Christian Medical University college; LDL: Low density lipoprotein; MMPs: Matrix metalloproteinases; MS: Metabolic syndrome; NIH: National Institutes of Health; NUFFIC: Netherlands Organization for International Cooperation in Higher Education; PCR: Polymerase chain reaction; US: United States; USA: United States of America

\section{Acknowledgements}

I would like firstly, to acknowledge the NUFFIC scholarship programme; $\mathrm{NIH}$ and the Health Resources and Services Administration award for their financial support. Secondly, my appreciations go to my Institutions - KCMC/ KCMUCo and the Free University, Amsterdam for providing the permission and mentorship to perform the research. Lastly but not least, I would like to thank all participants who willingly agreed to participate in this research.

\section{Funding}

This study was supported by the Netherlands Organization for International Cooperation in Higher Education (NUFFIC). Also JB receives salary support from the US National Institutes of Health Awards P30AI64518, U01AI067854, D43CA153722, and D43TW06732, and from the Health Resources and Services Administration Award T84HA21123. All authors contributed and revised manuscript drafts, and approved the final manuscript.

\section{Availability of data and materials}

All data generated or analyzed during this study are included in this published article as a supplementary information file and can be available in the Springer Nature Data Support Services repository, https://springernature.figshare.com/infd

\section{Authors' contribution}

All authors contributed to the design of the study. MVA, MVF, TF and GV performed data collection procedures and developed the dataset. TF, GV, YM, and MVA completed the review of literature, analyzed the data, and prepared the manuscript text. JB supervised data collection procedures, patient recruitment, and human subject protection. All authors read and approved the final manuscript.

\section{Ethics approval and consent to participate}

The study was approved by the Kilimanjaro Christian Medical University College (KCMUCo) Research Ethics Committee vide Ethical Clearance Certificate number 382.All participants signed the informed consent form after reading the information sheet before including them in the study.

\section{Conflict of interest}

The authors declare no conflicts of interest.

\section{Consent for publication}

Consent for publication was not requested from participants because no individual participant's data in any form such as images, voice recordings or videos are not included in this manuscript.

\section{Publisher's Note}

Springer Nature remains neutral with regard to jurisdictional claims in published maps and institutional affiliations.

\section{Author details}

${ }^{1}$ Department of Internal Medicine, Kilimanjaro Christian Medical Centre, Moshi, Tanzania. ${ }^{2}$ Department of Health and Nutritional Sciences, South Dakota State University, Brookings, SD, USA. ${ }^{3}$ VU University Medical Center, Amsterdam, The Netherlands. ${ }^{4}$ Duke University Medical Center, Durham, North Carolina, USA.

Received: 19 October 2017 Accepted: 19 December 2018 Published online: 29 December 2018

\section{References}

1. Grunfeld C, Delaney JAC, Wanke C, Currier JS, Scherzer R, Biggs ML, et al. Preclinical atherosclerosis due to HIV infection: carotid intima-medial thickness measurements from the FRAM study. AIDS. 2009;23:1841-9. 
2. van Wijk JPH, de Koning EJP, Cabezas MC, Joven J, op't Roodt J, Rabelink TJ et al. Functional and structural markers of atherosclerosis in human immunodeficiency virus-infected patients. J Am Coll Cardiol 2006;47:1117-1123.

3. Lorenz MW, Stephan C, Harmjanz A, Staszewski S, Buehler A, Bickel M, et al. Both long-term HIV infection and highly active antiretroviral therapy are independent risk factors for early carotid atherosclerosis. Atherosclerosis. 2008;196:720-6

4. Willum-Hansen T, Staessen JA, Torp-Pedersen C, Rasmussen S, Thijs L, Ibsen $\mathrm{H}$, et al. Prognostic value of aortic pulse wave velocity as index of arterial stiffness in the general population. Circulation. 2006;113:664-70.

5. Schillaci G, De Socio GV, Pucci G, Mannarino MR, Helou J, Pirro M, et al. Aortic stiffness in untreated adult patients with human immunodeficiency virus infection. Hypertension. 2008;52:308-13.

6. Schillaci G, De Socio GV, Pirro M, Savarese G, Mannarino MR, Baldelli F, et al. Impact of treatment with protease inhibitors on aortic stiffness in adult patients with human immunodeficiency virus infection. Arterioscler Thromb Vasc Biol. 2005:25:2381-5.

7. Lekakis J, Ikonomidis I, Palios J, Tsiodras S, Karatzis E, Poulakou G, et al. Association of highly active antiretroviral therapy with increased arterial stiffness in patients infected with human immunodeficiency virus. Am J Hypertens. 2009;22:828-34

8. Msoka TF, van Guilder GP, Smulders YM, van Furth M, Bartlett JA, van Agtmael MA. Antiretroviral treatment and time since HIV-1 diagnosis are associated with large artery stiffness in sub-Saharan African HIV-1 patients. Artery Research Journal. 2016;16:34-41.

9. Dau B, Holodniy M. The relationship between HIV infection and cardiovascular disease. Curr Cardiol Rev. 2008;4(3):203-18.

10. Joint United Nations Programme on HIV/AIDS (UNAIDS). Report on the global HIV/AIDS epidemic. Geneva: UNAIDS; 2008. Available from: http:// WWW.UNAIDS.org/globalreport/Global_report.htm.

11. Alberti KGMM, Eckel RH, Grundy SM, Zimmet PZ, Cleeman Jl, Donato KA, et al. Harmonizing the metabolic syndrome. A joint interim statement of the international diabetes federation task force on epidemiology and prevention National Heart, Lung, and Blood Institute; American Heart Association; world heart federation; international atherosclerosis society; and International Association for the Study of obesity. Circulation. 2009;120:1640-5.

12. Kim EJ, Park CG, Park JS, Suh SY, Choi CU, Kim JW, et al. Relationship between blood pressure parameters and pulse wave velocity in normotensive and hypertensive subjects: invasive study. J Hum Hypertens. 2007;21:141-8.

13. Townsend RR, Wilkinson IB, Schiffrin EL, Avolio AP, Chirinos JA, Cockcroft JR, et al. Recommendations for improving and standardizing vascular research on arterial stiffness: a scientific statement from the American Heart Association. Hypertension. 2015;66(3):698-722. https://doi.org/10.1161/HYP. 0000000000000033 Epub 2015 Jul 9

14. Lee D-H, Youn H-J, Chung W-B, Choi Y-S, Lee J-M, Park C-S, et al. Effects of metabolic syndrome on aortic pulse wave velocity. Clinical Hypertension. 2017:23(1). https://doi.org/10.1186/s40885-016-0057-6.

15. Scuteri A, Cunha PG, Cucca F, Cockcroft J, Raso FUM, Muiesan ML, et al. Arterial stiffness and influences of the metabolic syndrome: a crosscountries study. Atherosclerosis. 2014;233(2):654-60. https://doi.org/10.1016/ j.atherosclerosis.2014.01.041.

16. Rider OJ, Asaad M, Ntusi N, Wainwright E, Clutton G, Hancock G, et al. HIV is an independent predictor of aortic stiffness. J Cardiovasc Magn Reson. 2014; 16(57). https://doi.org/10.1186/s12968-014-0057-1.

17. Maloberti A, Giannattasio C, Dozio D, Betelli M, Villa P, Nava S, et al. Metabolic syndrome in human immunodeficiency virus-positive subjects: prevalence, phenotype, and related alterations in arterial structure and function. Metab Syndr Relat Disord. 2013;11(6):403-11. https://doi.org/10.1089/met.2013.0008.

18. Lowe GD. Virchow's triad revisited: abnormal flow. Pathophysiol Haemost Thromb. 2003;33(56):455-7.

19. Monsuez JJ, Charniot JC, Escaut L, Teicher E, Wyplosz B, Couzigou C, et al. HIV associated vasculardiseases: structural and functional changes, clinical implications. Int J Cardiol. 2009;133(3):293-306.

20. Ngatchou W, Lemogoum D, Ndobo P, Yiagnigni E, Tiogou E, Nga E, et al. Effects of antiretroviral therapy on arterial stiffness in Cameroonian HIVinfected patients. Blood Pressure Monitoring. 2013;18(5):247-51.

21. Awotedu $\mathrm{KO}$, Iputo J. A review of arterial stiffness and HIV infection in adult Africans. J Hypertens. 2016;5:2. https://doi.org/10.4172/2167-1095.1000221.

22. Singh J, Verma M, Ghalauta PS, Verma R, Sonid A, Ghalaut VS. Alteration in lipid profile in treatment-naive HIV-infected patients and changes following HAART initiation in Haryana. J Endocrinol Metab. 2014;4(1-2):25-31.
23. Barbaro G, lacobellis G. Metabolic syndrome associated with HIV and highly active antiretroviral therapy. Curr Diab Rep. 2009;9(1):37-42.

24. Hopps E, Caimi G. Matrix metalloproteinases in metabolic syndrome. European Journal of Internal Medicine. 2012:23:99-104.

25. Opstad TB, Arnesen H, Pettersen AA, Seljeflot I. The MMP-9-1562 C/T Polymophism in the presence of MS increases the risk of clinical events in patients with CAD. PLoS One. 2014;9(9):e106816. https://doi.org/10.1371/journal. pone.0106816.

26. Medley TL, Cole TJ, Dart AM, Gatzka CD, Kingwell BA. Matrix Metalloproteinase-9 genotype influences large artery stiffness through effects on aortic gene and Protein expression. Arterioscler Thromb Vasc Biol. 2004;24:1479-84.

27. Zieman SJ, Melenovsky V, Kass DA. Mechanisms pathophysiology, and therapy of arterial stiffness. Arterioscler Thromb Vasc Biol. 2005;25:932-43.

28. Visse R, Nagase H. Matrix metalloproteinases and tissue inhibitors of metalloproteinases: structure, function, and biochemistry. Circ Res. 2003;92:827-39.

29. Vlachopoulos C, Aznaouridis K, Dima I, loakeimidis N, Vasiliadou C, Zervoudaki A, et al. Negative association between serum levels of matrix metalloproteinases-2 and -9 and aortic stiffness in healthy adults. Int J Cardiol. 2007;122:232-8.

30. Vlachopoulos C, Dima I, Aznaouridis K, Vasiliadou C, loakeimidis N, Aggeli C, et al. Acute systemic inflammation increases arterial stiffness and decreases wave reflections in healthy individuals. Circulation. 2005;112:2193-200.

31. Vágovicová P, Mlikova Seidlerova J, Mayer O Jr, Wohlfahrt P, Cifkova R, Filipovsky J. Differential effect of metabolic syndrome on various parameters of arterial stiffness. Blood Press. 2015;24:206-11.

32. Cheng L-T, Tang L-J, Cheng L, Huang H-Y, Wang T. Limitation of the augmentation index for evaluating arterial stiffness. Hypertens Res. 2007; 30(8):713-22.

33. Holewijn S, den Heijer M, Stalenhoef AFH, de Graaf J. Non-invasive measurements of atherosclerosis (NIMA): current evidence and future perspectives. Neth J Med. 2010;68(12):338-99.

34. Kingery JR, Alfred Y, Smart LR, Nash E, Todd J, Naguib MR, et al. Short and long term cardiovascular risk, metabolic syndrome prevalence and HIV in Tanzania: a cross-sectional study. Heart. 2016;102(15):1200-5. https://doi.org/ 10.1136/heartjnl-2015-309026.

35. Kagaruki GB, Kimaro GD, Mweya CN, Kilale AM, Mrisho RM, Shao AF, et al. Prevalence and risk factors of metabolic syndrome among individuals living with HIV and receiving antiretroviral treatment in Tanzania. British Journal of Medicine \& Medical Research. 2015;5(10):1317-27.

36. Wannamethee SG. The metabolic syndrome and cardiovascular risk in the British regional heart study. Int J Obes. 2008;32(2):25-9.

37. Pullinger CR, Aouizerat BE, Gay C, Coggins T, Movsesyan I, Davis H, et al. Metabolic abnormalities and coronary heart disease risk in human immunodeficiency virus-infected adults. Metab Syndr Relat Disord. 2010; 8(3):279-86. https://doi.org/10.1089/met.2009.0094.

38. Mozumdar A, Liguori G. Persistent increase of prevalence of metabolic syndrome among U.S. adults: NHANES III to NHANES 1999-2006. Diabetes Care. 2011;34(1): 216-9. https://doi.org/10.2337/dc10-0879. Epub 2010 Oct 1 (2011).

39. Malangu N. Factors associated with metabolic syndrome among HIV positive patients at health facility in Botswana. British Journal of Medicine and medical Research. 2014;4(12):2352-61.

40. Muyanja D, Muzoora C, Muyingo A, Muyindike W, Siedner MJ. High prevalence of metabolic syndrome and cardiovascular disease risk among people with HIV on stable ART in southwestern Uganda. AIDS Patient Care STDs. 2016;30(1). https://doi.org/10.1089/apc.2015.0213.

\section{Ready to submit your research? Choose BMC and benefit from:}

- fast, convenient online submission

- thorough peer review by experienced researchers in your field

- rapid publication on acceptance

- support for research data, including large and complex data types

- gold Open Access which fosters wider collaboration and increased citations

- maximum visibility for your research: over $100 \mathrm{M}$ website views per year

At $\mathrm{BMC}$, research is always in progress.

Learn more biomedcentral.com/submissions 